\title{
Functional Perspective in Drama Translation: A Case Study of Translating Courting Passages in a Canonical Chinese Play
}

\author{
Ann-Marie Hsiung \\ I-Shou University, Kaohsiung, Taiwan
}

\begin{abstract}
This study explores some complex issues of drama translation — whether it should be treated as literary translation or not-by investigating two English translations of the same canonic Chinese drama, Xixiang ji. One translation claims to be literature piece while the other, stage-script. In comparing the two of different function and discussing their specific divergent expressions, this paper intends to shed some light on drama translation. It examines the translators' purpose that closely links to their translation strategy and the function of their translation, followed by sample translations of courting passages. It illuminates the relative strength and weakness of drama translation as literature and as stage-script.
\end{abstract}

Keywords: functional theories, text type, skopos, intercultural communication, gender reversal

It has been long debated whether drama translation should be differentiated from other forms of literary translation. Susan Bassnett, for instance, has argued for the necessity of differentiation; after exploring the complexity of drama translation in general and the uncertainty of its performability in particular, however, she then proposes to translate drama as literature (1980/2002, p. 119; 1998, p. 107). This study explores further issues of drama translation by examining two English translations of the same canonic Chinese drama Xixiang $j i$ - one for page while the other for stage—-from functional perspective.

Ever since the "cultural turn" in translation studies, the "much neglected" drama translation has begun to draw academic attention (Bassnett, 1998, p. 90). Broader cultural factors surrounding translation gradually came to the fore in translation studies. This study focuses on cultural and functional aspects of drama translations from the perspective of functional theories, mainly Katharina Reiss' text type (1977/1989) and Hans J. Vermeer's skopos theory (1989/2004). It briefly introduces the above theories, the source play Xixiang ji, and then proceeds with case study - the purpose of the translators and sample translations of courting passages.

Functional theorists view translation as activity of intercultural communication; translation methods are decided by text type and the functional purpose of translation. For Reiss (1977/1989, pp. 113-114), communication is achieved by the level of text rather than word or sentence, and the equivalence is sought on text level. She offers three basic text types and provide specific translation method for each. They are informative, expressive and the operative texts; in terms of translation, the three types are classified as content-focused to transmit referential content, form-focused to transmit aesthetic form, and appellative-focused to elicit desired

Ann-Marie Hsiung, Ph.D., Associate Professor, Department of Applied English, I-Shou University, Kaohsiung, Taiwan. 
response (Reiss, 1977/1989, pp. 108-109). According to Reiss's text type, literature, especially poem and play, belongs to expressive type and the translator's job is to closely follow the form and aesthetics of the source text taking in author-centered perspective. Vermeer in his skopos theory proclaims that the purpose of translation decides translation strategy and thus the outcome of translation (1989/2004, p. 228). He shifts the focus to the purpose of translation stressing the communicative action of translation. For Vermeer, a target text should be fit for purpose. It heightens the role of the translator as "the key player in a process of intercultural communication and production” (Munday, 2012, p. 213). The skopos theory tends to highlight the translator's subjectivity by recognizing that they make certain choices for the specific purpose and function of the translation. To be functionally adequate, the expertise of the translator is crucial. The method of drama translation is broadened here. According to skopos theory, the objective and function of translation are to fulfill the needs of the target culture; the translation methods would be target-orientated rather than source orientated.

\section{Contextualising the Canonical Chinese Drama Xixiang ji}

Xixiang ji 西廂記, better known as Romance of the Western Chamber, the play in question, is one of the finest literature and artistic productions of Yuan dynasty (1279-1368), the golden age of Chinese drama. Cyril Birch, the well-known scholar of Chinese literature and drama, makes such remark:

Yüan drama is at once the first full florescence, the Golden Age and the grand classical forebear of all Chinese theatre. In performance, the most we could hope to see of it today would be a reconstruction of its lost music and largely unknown stage conventions... (1976, pp. v-viii)

Yuan drama, more often termed as zaju ("variety show" in its literal meaning), is a form of traditional poetic music drama; the zaju theater was a combination of Chinese art, music, and poetry (or libretto as many of them are acted out in singing) in addition to dialogues. While Xixiang ji is most well-known by its love story, comparable to that of Romeo and Julia in the Western drama (Xu, 2000/2008, pp. 23-25), it is the superb literary expression in poems, libretto, and vernacular language presented in courtship that makes this drama memorable and highly influential.

Xixiang ji has unmatched reputation in China as dramatic literature and performing arts despite the constant official ban due to the explicit sexual scenes. Since Wang Shifu's (ca. 1250-1300) composition of this masterpiece, it has become instantly popular; it hence engendered numerous reproductions, imitations, parodies, and adaptations, both for closet reading and theatrical performance. For instance, the Ming dynasty (1368-1644) playwright Cui Shipei and Li Rihua adapted Wang's original zaju libretto into the then mainstream chuanqi music, and thus promoted the play and prolonged its stage life, especially after zaju ceased to be performed in opera houses. Apart from its domestic influence, this drama has reached to global audience via translations and academic studies.

The rise of drama to amount the golden age in Yuan China has to do with the Mongol rule. Marked as the first non-Han dynasty, the Mongol ruling class, not erudite in Confucian classics or classic language, was in favor of vernacular language and theatre. Furthermore, the founding emperor of Yuan abolished the civil service examination, the path to officialdom for Confucian scholars. Blocked by the usual career path, many talented literati turned into playwrights. Drama of Yuan thus reached a new height combining characteristics of vivid vernacular speech and erudite classic poems. Moreover, as scholar playwrights were marginalized or feminized 
in social advancement, they tended to have "authorial representation" (Jiang, 1991, p. 33) in their construction of women, the inferior class as themselves. The superior women are commonly represented in Yuan drama. The selected sample translations would offer a glimpse into such phenomenon, though the focus here is more on the weaker male.

Such a classic play comprising of largely poems/libretto is obviously expressive text in Reiss' text type theory; the translators are supposed to take "identifying' method" (Munday, 2012, p. 112) which is author-centered making the maximum effort to transmit the artistic form and aesthetic quality of the source play. This seems to be in line with one of Bassnett's later views of translating drama as literature. However, one may question whether the outcome of such translation fit for stage performance of different culture, time, and space. Playwrights usually have performance in mind while writing their plays, though not a small portion of dramatic works is read and appreciated as classic literature after obtaining canonic status. In history, traditional Chinese dramas were introduced to the Western world more as literature than as performing art, perhaps due to the complexity and challenges involved in stage performance. This study intends to illustrate with examples the intercultural communication of this canonical Chinese drama in the English world. It examines two translations of divergent functions - the reader-oriented version The Story of the Western Wing (1991/1995) by Stephen H. West and Wilt L. Idema, and the audience-oriented one The West Wing (2008a) by Grant Shen.

\section{The Translators' Purpose (Skopos) and Their Corresponding Strategy}

To translate such traditional Chinese drama full of classic poems, archaic expressions and allusions, the qualification of the translators are essential. The translators of the two versions mentioned are all scholars of classic Chinese literature, though their primary expertise varies. West and Idema are well-known sinologists based in US when team-working on the translation, while Grant Shen is Asian theatre specialist based in Singapore during the translation and production of The West Wing. West-Idema version is believed to be the most complete and authentic among all the extant translations of Wang's original play (West \& Idema, 1991/1995, p. 5; Jiang, 2009, p. 419). Shen's appears to be the first stage translation, though his source play deviates from West-Idema for his functional purpose. Rather than abiding closely to the full play by Wang, Shen followed the structure and dialogue of Li Rihua's chuanqi adaptation of the Ming dynasty while translating his lyrics directly from Wang Shifu's zaju libretto of the Yuan dynasty. These translators' statement either in their book introduction or performance pamphlet help further understand their purpose and translation strategy.

West and Idema make their purpose and approach of translation clear in their extensive 100-page introduction. They write: "Our aim...is to provide the Western reader with a rendition that is as close to the original as a literary translation will allow, warts and all” (1991/1995, p. 15). Abiding to the age-old translation notion of faithfulness, they value the original Chinese play and wish to present it to the Western world as truthfully as they can. Acknowledging that their version may appear excessively literal to some, West and Idema claim: "we have been guided by the belief that it is both unnecessary and undesirable to resort to well-worn English equivalents or clichés to smooth over any passages that challenge the reader to active engagement" (1991/1995, p. 15). As suggested by Reiss for translating the expressive text type, West and Idema have taken "identifying" method together with foreignization strategy attempting to transmit the aesthetic and unique cultural expressions of the source play. In order to engage Western readers in the traditional Chinese literary 
world, their English translation sometimes appears non-fluent or archaic, perhaps for the special effect of this mediaeval Chinese drama.

Grant Shen's version displays a purpose far different from West-Idema's rendition. Contrary to West and Idema's aim to bring Western readers into the Asian masterpiece by maximum fidelity to the source text, Shen makes an effort to bring the traditional Chinese drama into the English speaking audience by selective deviations from the source play, purposeful adoption of Western pop music, and resorting to colloquial modern English. Interestingly, Shen also claims to be abiding by the spirit of the source play as performed in pre-modern China. He states:

\footnotetext{
I wanted an authentic experience of golden-age Chinese opera for the audience, meaning that a modern theater-goer may enjoy the show as a Ming Chinese did 400 years ago. I did not want to present a piece of museum art that is authentic in form, but lacking in both the vitality of contemporary life and the entertainment value that are imperatives in popular theatre.
}

...In the heyday of Chinese opera, the audience enjoyed music contemporary to their time... (Shen Dir., 2008a, p. 2)

Shen transforms the old Chinese into fluent and trendy English today to arouse an immediate response from the audience. Moreover, the entertainment value of popular theatre is Shen's primary purpose, thus making his adoption of popular Western music justifiable. Far from Reiss's proposed identifying method to translate expressive text type as drama, Shen's approach appears to be "adaptive” with equivalent effect-translation method opted by Reiss for operative text type like advertisement. Reiss' text type theory is inadequate to explain Shen's translation strategy. Other functional theorists such as Vermeer's skopos theory, nonetheless, helps to supplement this insufficiency as the purpose overrides text type with its corresponding translation method. As noted by Munday: "What is functionally suitable has to be determined by the translator, who is the expert in translatorial action and whose role is to make sure that the intercultural transfer takes place satisfactorily" (2012, p. 121). Viewing from Shen's functional purpose, it is interesting to note that a traditional drama translated for contemporary stage shares similar function with operative text in terms of appealing to the receivers and eliciting desired response. Sample translations of courting passages from the source plays are discussed below.

\section{Sample Translations of Courting Passages}

As mentioned, women in Yuan zaju often appear more superior than men likely due to the marginalized/feminized playwrights' self-representation. The so-called "gender reversal” scenes are frequently seen in Yuan drama, in which women are stronger in mind and spirit than their male counterpart. The male lead, usually the Confucian scholar, is usually displayed as weaker gender, especially under the spell of love. Xixiang ji is no exception. It tells the love story of a travelling scholar Zhang Gong and the gentry young lady Yingying, who takes a temporary lodge at Pujiu Temple with her widow mother (Madam Cui) and her maidservant Hongniang (rendered as Crimson by West-Idema and Scarlet by Shen). Zhang is on his way to take the imperial examinations, setting lofty goal of a bright official career. Once meeting Yingying, however, Zhang abandons his ambition and surrenders completely to her beauty. Madam Cui, the strong matriarch, objects their love, while Hongniang acts as their witty liaison. In the compound of Pujiu Temple, Zhang's masculine ambition turns into the perceived feminine trait of emotional breakdown and physical weakness in his lovesickness. He is subject to female power, as his masculinity is rescued by Hongniang and Yingying. 
The sample translations to be discussed are taken from courting passages, mainly dialogue and poems that display above-mentioned "gender reversal”. After Madame Cui's break of her promise to have Zhang marry Yingying, Zhang kneels and weeps to Hongniang, begging for sympathy and help. Throughout the scene, Zhang and Hongniang exemplify perfect gender role reversal. Zhang remains a helpless victim of love, vulnerable and feminine in his state of mind, while the maidservant Hongniang stands strong as masculine savior. The short passage below vividly expresses Zhang's lovesickness to the extent of willingly ending his life in front of Hongniang. It follows by ST, West-Idema and then Shen version:

小生為小姐書夜忘餐廢寝, 夢斷魂勞, 常忽忽如有所失。……甫能得成就, 不料夫人變了掛, 使小生智竭思 窮……小娘子, 怎生可憐見小生。（跪貼介）將此意伸與小姐, 使知小生之心。就小娘子前, 解下腰間之帶, 尋 個自盡。(Wang, 2001, p. 415; Li, 2001, pp. 557-558)

(Male lead kneels before Crimson and speaks:) Because of your missy, day and night I forget to eat and I give up sleep. My soul is wearied, my dreams are broken, and I'm constantly distracted as if I'd lost something. ....Barely had we achieved some success when the old lady changed her stripes. Now I am at wits' end.... Young lady, please have pity on me and tell my thoughts to your missy so she may know my heart. And now, right in front of you, I will take off my belt and hang myself. (West \& Idema, 1991/1995, p. 182)

...Because of your Young Mistress, I've not been able to sleep or eat. What I’ve won, Madam has taken away. Life is not worth living. Take pity on me! Tell your Young Mistress, I'll kill myself for love of her. [Zhang kneels and unties his cloth belt] (Shen, 2008b, p. 23)

Apparently, West-Idema's source-centered identifying method renders a far longer TT than Shen's target-oriented adaptive method. Compared to West-Idema's literal and literary translation, Shen's adaptation for stage is much shorten and forceful. One obvious adaptation is to change the final line into stage action instead of Zhang's continued narration to Hongniang. The West-Idema version serves their primary purpose for full-scale literary reading, while Shen's maintains efficacy for stage performance. Both versions clearly display the love-stricken Zhang who loses his senses and is ready to pledge his life for love's sake; their representations, however, achieve different levels of equivalence.

West-Idema's author-oriented approach is in line with formal equivalence. They do render their translation as close to the source play as can be. They enable the readers to read their version as if reading the source play. They allow keen readers to experience the full wealth of classic dramatic literature. Their version adopts some archaic expressions to remind the Western readers that they are reading into an ancient scholar's lament for love. Nonetheless, this literal translation is not free from minor mismatches in translation. To have Zhang address Yingying as "missy" might be understandable or acceptable during the latter development of courtship, provided that the translators wish to hint on Zhang's intimacy with Yingying. Yet "missy" seems too informal for the source term “xiaojie 小姐”, and too imposing for the character to attempt that intimacy in the initial stage of courtship. In addition, to have Zhang address Hongniang, Yingying’s maidservant, as “young lady” (xiao niangzi 小娘子 in the source term) appears inappropriate in view of the source language and the native culture. By all accounts, “young lady” would naturally match "xiaojie” and "missy”, the less formal expression, "xiao niangzi”. In this case, postmodern perception may have infused into this classic play’s translation; translators' intended fidelity to the Chinese source text seems evaded. 
On the contrary, Shen's target-oriented approach appears akin to dynamic/functional equivalence. Rather than the maximum effort of word for word and line for line like the West-Idema version, Shen boldly cuts short the source text and renders it in fluent English, which paradoxically appears to fit better in the vernacular expression of the source dialogue. With plenty of deletion and transformation, the Shen version suits the audience for the instant gist of the play, and most importantly it fulfills the function of performance. For instance, Shen uses "life is not worth living" to replace many of Zhang’s literary narration of love-sickness. Shen appears to purposefully shorten the stage narration for the constraint of performance time. By adopting colloquial and trendy English, the distance between pre-modern scholar Zhang and contemporary audience is shortened; the representation of Zhang has become one that the audience members can easily identify with and connect to.

Zhang's behavior no doubt deviates from the patriarchal norm of Confucianism. What's more, his love for Yingying is infused with strong sex desire. Though love and sex in traditional China is not usually dichotomously set apart, restraint from sex is a dominant Confucian value. Driven by love, Zhang willingly forsakes gender hierarchy. Taking Hongniang’s suggestion, Zhang first tries to move Yingying’s heart by playing seductive music, followed by love letter, including a poem at the end. In the letter, Zhang appeals to her sympathy of his predicament and calls for her action, as represented by West-Idema and Shen respectively:

患成思竭, 垂命有日……萬一有見憐之心, 乞惠好音賜下, 庶幾可保殘喘

……此情不可遲, 虛譽何需奉? 莫負月華明, 且憐花影重。(Wang, 2001, p. 436; Li, 2001, p. 574)

My frustrations are complete, my thoughts exhausted, and my life hangs every moment in the balance. ...If, by some miracle, you feel a little pity, please write to me so that I can still nurse myself back to health. ...

Such passion cannot be denied;

What need to cling to empty reputation?

Do not betray the brightness of moon's blossom;

But covet the heaviness of flowers’ shadows. (West \& Idema, 1991/1995, pp. 195-196)

The sickness accumulates and weakens my mind. It drains my vitality. Before my days' end, I would convey a few words in the faint hope of having your sympathy on this worthless man, so that his final breath may be sustained. ...

The flames of passion cannot be tame.

Reputation is but an empty name.

Let us take the moonlight when we may,

Let the shadows of flowers inter-play. (Shen, 2008b, pp. 25-26)

In the letter, Zhang foregoes his male pride and humbles himself to Yingying, beseeching for commiseration of his life-threatening lovesickness. Shen's rendition of the love letter appears to resonate better with the terse classic Chinese expression of Zhang's desperate emotion, which is not readily detectable in West-Idema's literal translation. In plain and brisk English, Shen's version accentuates Zhang's self-pity by adding some words like "this worthless man" referred by Zhang to himself. The addition of such line happens to correspond to feminist translation strategy of supplementation (von Flotow, 1997, pp. 27-28). It further castes down Zhang's male-ego and makes the hero appears inferior to the heroine.

In the poem, Zhang pleas Yingying to follow her heart, rather than the etiquette. Clearly, West and Idema follow Chinese word structure and syntax much more closely than Shen. For the last four lines of the love poem, both translations appear equally superb, while Shen's rhymed verse serves the singing purpose of an opera house. Nevertheless, Shen's choice of “inter-play” (chong 重) in the final line seems superior to “heaviness” (zhong 重) 
used by West and Idema, who appear to have picked the wrong meaning of the polysemant character 重. Shen's final line vividly hints Zhang's entreaty for physical union, while West-Idema's divorces from the intended meaning of the source text. However, the surprising poetic imagery of "heaviness of flowers' shadows" may indeed serve their aim of engaging readers' active imagination.

During the courtship, Yingying is represented as a savior, while Zhang the victim of love. Zhang becomes critically ill after Yingying's reprimand of his “uninvited” night visit upon a punning poem sent by Yingying. His illness proves incurable by any medical doctors except Yingying herself. To rescue Zhang, Yingying composes a poem of punning prescription of sex overtone for Zhang. The prescription becomes the romantic remedy that saves Zhang's life. The first two lines of the prescription in the translations of West-Idema and Shen read:

\section{桂花摇影夜深沉;}

酸醋當歸浸。(Wang, 2001, p. 472; Li, 2001, p. 607)

Cassia flowers sway their shade in the dead of night;

Vinegar soaks the one who “ought to return.” (West-Idema, 1991/1995, p. 219)

Sway the sweet Cassia at midnight,

Soak angelica root in honey moon's light; (Shen, 2008b, p. 33)

The translation of such punning poem is highly challenging as the source language expressions contain double or even multiple meanings. English translation can only take on one layer of meaning. For instance, West-Idema's version takes the literal one to translate danggui 當歸, a common Chinese herb, according to the individual word meaning as "ought to return”, which would have puzzled an average reader. Shen's version is not at all literal, yet it appears closer to the subtext of the original; it also provides a more poetic imagery of the metaphor, which is enhanced by the rhyming. Moreover, in order to make audience fully understand, Shen version supplements Zhang's interpretation of Yingying's hidden meaning to Hongniang line by line, and these two lines become as explicit as: "Come and embrace her at midnight. She allows me to taste the forbidden fruit” (2008b, p. 34). Such layers of meaning, however, are difficult to be perceived in West-Idema version.

Yingying's poem in her love letter to Zhang is brilliantly and boldly composed. It is a pity that Shen version has skipped this poem, which is well presented in West-Idema's version:

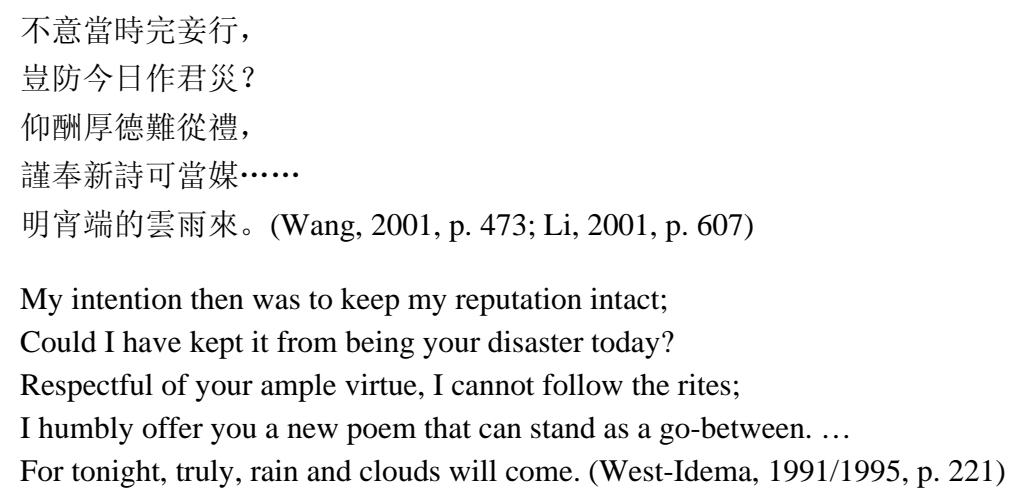

Yingying dutifully explains her earlier act of rejection, and unambiguously promises sex with Zhang. West-Idema's translation is as brilliant as the source text. Nevertheless, "rain and clouds", an obvious example of 
foreignizing and literal translation, may not be readily intelligible for the readers, though this phrase has been explained as "a metaphorfor sexual intercourse" (1991/1995, p. 67) in the introduction and earlier notes. It is undeniably an intercultural learning experience to acquire a foreign classic expression; however, one may wonder: How many modern-day readers would be so engaging as to check cross-reference in the much earlier pages?

\section{Conclusion}

As shown, the translators' purposes determine the function and outcome of their translation; the same source play can generate diverse representations. The above discussion reveals that to better comprehend the canonical Chinese drama Xixiang ji, it is important to consult translations of different purposes. Bassnett's dilemma regarding drama translation to be performability-oriented or as literature appears to be derived from a dichotomous mindset. Such issues are not at all problems when taken from functional perspective. Functional theories, though not without flaw, allow drama translators liberty to set their functional purposes and to carry out in view of intercultural communication.

Between the two translations, West-Idema version appears to perfectly illustrate Reiss' model of translating expressive text type. It is also the most acclaimed version among scholars; it has received complements such as rendering the text "with scrupulous exactness", translating "as faithfully as can be done” (Birch, 1976, p. xi). Nonetheless, by taking identifying method to preserve the aesthetic form and source cultural expressions, West and Idema are at the expense of rhyme, thus rendering the libretto unsingable and the TT not as formal equivalent as they set out to be. This is, nevertheless, not as much an issue as they aim for page (readers).

Interestingly, to translate the traditional Chinese play for the contemporary stage, Xixiang ji, the predominantly expressive text type, can become more as operative text type which allows the translator to take further liberty to adapt in order to appeal to audience. Shen's many adaptations or even addition in his translation, however, at times appear closer or even more authentic to the source meaning.

The two translations have fairly represented the reversed gender roles during the courtship in the play. West-Idema's aim and approach lead to a version much more formal and elegant than Shen's though at times too literal to be readily comprehended. Shen's on the other hand, features the dynamic quality and equivalent effect of the play, which nonetheless can easily fall into translator's manipulation.

It is fair to say that West-Idema's literary translation provides great service to serious readers and scholars. As for Shen's stage version, though far from literal or literary translation, it instills vitality into the age-old Asian masterpiece and makes Xixiang ji re-live in a contemporary context.

\section{References}

Bassnett, S. (1980/2002). Translation studies. London: Routledge.

Bassnett, S. (1998). Still trapped in the labyrinth: Further reflections on translation and theatre. In Constructing culture: Essays on literary translation (pp. 90-108). Clevedon, UK: Multilingual Matters.

Birch, C. (1976). Foreword. In C.-W. Shih, Golden age of Chinese drama: Yuan Tsa-chu (pp. v-viii). Princeton: Princeton University Press. Retrieved from www.jstor.org/stable/j.ctt13x1352.2

Jiang, T.-F. (1991). Gender reversal: Women in Chinese drama under mongol rule (1234-1368) (Diss. U of Washington).

Jiang, X. Y. (2009). The studies and appreciation of Xixiang ji. Shanghai, China: Shanghai People's Publishing House.

Li, R. H. (2001). The southern Xixiang ji. In Z. S. Huang and J. J. Huang (comp.), The commentary on sixty chuanqi plays (pp. 439-722). Jilin, China: People’s Publishing House. 
Munday, J. (2012). Introducing translation studies: Theories and applications (3rd ed.). London and New York: Routledge.

Reiss, K. (1977/1989). Text types, translation types and translation assessments. In A. Chesterman (Trans.) (Ed.), Reading in translation theory (pp. 105-115). Helsinki: FinnLetura.

Shen, G. Dir. (2008a). The west wing: A renaissance production with modern music and dance. Singapore: National University of Singapore.

Shen, G. Dir. (Trans.). (2008b). The west wing: A chuanqi opera. Ms. 1-44. Singapore: National University of Singapore.

Vermeer, H. J. (1989/2004). Skopos and commission in translational action. In L. Venuti (Ed.), The translation studies reader (pp. 221-232). London and NY: Routledge.

Von Flotow, L. (1997). Translation and gender: Translating in the era of feminism. Manchester: St Jerome.

Wang, S. F. (2001). Xixiang ji. In Z. S. Huang and J. J. Huang (comp.), The commentary on sixty chuanqi plays (pp. 327-628). Jilin, China: People’s Publishing House.

West, S., \& Idema, W. (Trans.). (1991/1995). The story of the western wing. Berkeley: U of California P.

Xu, Y. C. (Trans.). (2000/2008). Preface. In Romance of the western bower (pp. 17-26). Hunan, China: Hunan People's Publishing House. 